\title{
Standardized evaluation of lung congestion during COPD exacerbation better identifies patients at risk of dying
}

This article was published in the following Dove Press journal:

International Journal of COPD

5 December 2013

Number of times this article has been viewed

\section{Arne Didrik Høiseth ${ }^{1}$ \\ Torbjørn Omland' \\ Bo Daniel Karlsson ${ }^{2}$ \\ Pål H Brekke' \\ Vidar Søyseth'}

'Cardiothoracic Research Group, Division of Medicine, Akershus University Hospital and Institute of Clinical Medicine, University of Oslo, Oslo, Norway; ${ }^{2}$ Department of Radiology, Akershus University Hospital, Lørenskog, Norway
Correspondence: Arne Didrik Høiseth Akershus University Hospital and Institute of Clinical Medicine, University of Oslo, I 478 Lørenskog, Oslo, Norway Tel +4767968800

Email a.d.hoiseth@medisin.uio.no
Background: Congestive heart failure is underdiagnosed in patients with chronic obstructive pulmonary disease (COPD). Pulmonary congestion on chest radiograph at admission for acute exacerbation of COPD (AECOPD) is associated with an increased risk of mortality. A standardized evaluation of chest radiographs may enhance prognostic accuracy.

Purpose: We aimed to evaluate whether a standardized, liberal assessment of pulmonary congestion is superior to the routine assessment in identifying patients at increased risk of long-term mortality, and to investigate the association of heart failure with $\mathrm{N}$-terminal prohormone of brain natriuretic peptide (NT-proBNP) concentrations.

Material and methods: This was a prospective cohort study of 99 patients admitted for AECOPD. Chest radiographs obtained on admission were routinely evaluated and then later evaluated by blinded investigators using a standardized protocol looking for Kerley B lines, enlarged vessels in the lung apex, perihilar cuffing, peribronchial haze, and interstitial or alveolar edema, defining the presence of pulmonary congestion. Adjusted associations with long-term mortality and NT-proBNP concentration were calculated.

Results: The standardized assessment was positive for pulmonary congestion in 32 of the 195 radiographs (16\%) ruled negative in the routine assessment. The standardized assessment was superior in predicting death during a median follow up of 1.9 years $(P=0.022)$, and in multivariable analysis, only the standardized assessment showed a significant association with mortality (hazard ratio $2.4,95 \%$ confidence interval [CI] 1.2-4.7) $(P=0.016)$ and NT-proBNP (relative concentration 1.8, CI 1.2-2.6) ( $P=0.003)$.

Conclusion: By applying a standardized approach when evaluating pulmonary congestion on chest radiographs during AECOPD, a group of patients with increased risk of dying, possibly due to heart failure, is identified.

Keywords: heart failure, radiograph, NT-proBNP, mortality, X-ray, cephalization

\section{Background}

During recent years, increasing attention has been paid to the role of comorbidities in patients with chronic obstructive pulmonary disease (COPD). Cardiovascular diseases (CVD) are among the extrapulmonary manifestations of COPD. The incidence of and mortality from CVD, such as cerebral stroke, myocardial infarction (MI), heart failure (HF), and arrhythmias are higher among COPD patients than in the general population, even after adjusting for smoking and other important confounders. ${ }^{1-4}$ Accordingly, increased awareness of concomitant CVD in COPD is warranted. In review articles on the use of new radiological imaging modalities in COPD, particular attention is paid to the presence of emphysema, bronchiectasis, or vascular remodeling. ${ }^{5,6}$ 
There is little emphasis on the signs of heart disease and what can still be learned from the standard chest radiographs, though this remains central in the diagnosis of $\mathrm{HF}^{7}$ Reportedly, only $16 \%$ of chest radiographs taken during acute exacerbation of COPD (AECOPD) show abnormal findings, ${ }^{8}$ but when observed, these are findings that will have therapeutic consequences. Pulmonary congestion, a sign of congestive HF, is among the abnormalities that can be found. $\mathrm{HF}$ is associated with increased mortality, although effective treatment exists. However, it has been shown that heart disease often remains undiagnosed in COPD patients, ${ }^{9-11}$ Therefore, radiographic evidence of such could be important to the clinicians.

In a previous study, we found that signs of pulmonary congestion on chest radiographs taken on admission for AECOPD was strongly and independently associated with long-term mortality. ${ }^{12}$ These radiographs were investigated by dedicated study physicians, and the prevalence of pulmonary congestion on admission was $16 \%$. Our impression was that in everyday practice, radiological signs of HF remain undetected in a high proportion of COPD patients.

The natriuretic peptides B-type natriuretic peptide (BNP) and the amino terminal fragment of the BNP prohormone (NT-proBNP) are established markers of HF. ${ }^{7}$ BNP and chest radiographs have been found to be independently associated with HF in patients presenting with acute dyspnea. ${ }^{13}$ Both BNP and NT-proBNP are independently associated with worse prognosis during and after AECOPD. ${ }^{14-17}$

Radiological evaluation of HF in patients with COPD may be difficult. ${ }^{18}$ Therefore, in the present study we wanted to a) investigate whether a standardized investigation of pulmonary congestion on chest radiograph taken on admission for AECOPD could predict mortality better than routine evaluation of the radiographs, and b) validate the standardized assessment with regard to the presence of HF, as evaluated by NT-proBNP levels.

\section{Methods}

During 23 months in 2005 and 2006 we prospectively included 99 unselected patients as they were admitted with AECOPD. Among these, 41 patients had data recorded on one or more readmissions during the inclusion period, and in total, we gathered data from 219 admissions. The details regarding patient inclusion and data gathering have been described in previous papers. ${ }^{12,19}$ On admission, we recorded medical history, clinical data, electrocardiograms (ECG), and chest radiographs. In addition to a qualitative analysis of prior MI (pathological Q, loss of R, and T inversion) and acute ischemia (ST segment depression or elevation), the ECG analysis included a cardiac infarction injury score (CIIS), where a score $\geq 20$ indicates high probability of prior $\mathrm{MI}{ }^{20}$ In one study of COPD patients without a history of CVD, CIIS $\geq 20$ was associated with increased mortality. ${ }^{9}$ The ECG analyses were conducted by two independent investigators blinded for all other information, and discrepancies were settled by a third investigator.

Chest radiographs were obtained routinely on admission, the standard being posteroanterior and lateral projections. In clinically deranged patients unable to cooperate or stand up, only the frontal plane image with anteroposterior projection was obtained. For the "standardized assessment," the radiographs were examined by two of the investigators, a pulmonologist, and a radiology fellow, blinded to all clinical data. In each case, they cooperated to determine the presence or absence of Kerley B lines, enlarged vessels in the lung apex (redistribution), peribronchial cuffing, perihilar haze, and interstitial or alveolar edema. If any of these features were present, it was considered positive for pulmonary congestion. The investigators also recorded the presence of infiltrates and pleural effusions. On admission, the radiographs had routinely been examined by first the radiology fellow on call and then by one of the senior radiologists (a minority of the radiographs were evaluated by a senior radiologist only). The radiologists were unaware that the patient under investigation was to be included in any study. Their descriptions ("routine assessment") therefore reflect the normal everyday radiologic evaluation and were retrieved from the hospital's electronic records, and it was noted whether or not pulmonary congestion had been reported.

Blood collected on admission was stored at $-80^{\circ} \mathrm{C}$ for subsequent analysis of NT-proBNP and creatinine concentrations. From the hospital records, we also recorded the discharge diagnoses with regard to concomitant HF or infection (International Classification of Diseases [ICD]-10 codes I50 or J10-22). ${ }^{21}$ The patients were followed with respect to survival until the end of 2008 or death.

The study was approved by the Data Inspectorate and the Regional Ethics Committees South East. All patients provided written informed consent.

\section{Statistical analyses Baseline analyses}

Using the 99 baseline observations, we first analyzed the crude mortality rates associated with the two radiological assessments and compared them using a logrank test. We also calculated the two assessments' sensitivity and specificity for 
identifying patients at risk of death during the observation period and compared the two assessments, using receiveroperating characteristics (ROC).

For both radiological assessments, we then investigated the univariable baseline associations between pulmonary congestion and covariables. We compared clinical and biochemical data in these groups, using the Kruskal-Wallis test for continuous variables (age, body mass index [BMI], forced expiratory volume in 1 second/forced vital capacity $\left[\mathrm{FEV}_{1} / \mathrm{FVC}\right]$ ratio, mean arterial pressure, serum creatinine, leucocyte count, serum C-reactive protein [CRP], hemoglobin, heart rate, arterial oxygen saturation $\left[\mathrm{SaO}_{2}\right]$, arterial partial pressures of $\mathrm{O}_{2}$ $\left[\mathrm{PaO}_{2}\right]$ and $\mathrm{CO}_{2}\left[\mathrm{PaCO}_{2}\right]$, and arterial $\mathrm{pH}$ ) and chi-square or Fisher's exact test for categorical data (smoking status [current or recent versus previous or never], history of coronary artery disease, HF, diabetes mellitus, and arterial hypertension, atrial fibrillation, peripheral edema, and chest pain on admission, patient posture, infiltrate on chest radiograph, and prior MI, acute ischemia, and CIIS $\geq 20$ in ECG).

\section{Bivariable analyses}

If patients with and without pulmonary congestion had different values of a covariable in any radiological assessment $(P<0.20$ in the baseline analyses), this covariable was investigated with regard to an association with mortality and NT-proBNP concentration.

\section{Analysis of mortality}

To investigate the association between the relevant covariables and mortality, we calculated the mortality rates in each category of the covariables, with continuous variables categorized by quartiles, and compared these with survival, using an age-adjusted logrank test.

\section{Analysis of NT-proBNP}

Due to the skewed distribution of NT-proBNP concentrations, the natural logarithm of the NT-proBNP concentration (lnBNP) was used as the dependent variable in these analyses. The associations between $\ln \mathrm{BNP}$ and the relevant categorized covariables were then compared using Student's $t$-test or analysis of variance (ANOVA). In each category of the covariables, we also calculated the geometric mean of NT-proBNP concentration, that is, the antilog of the mean $\operatorname{lnBNP}$ value.

\section{Multivariable analyses}

In the baseline and bivariate analyses, only the 99 baseline observations were included in the analyses. However, for the multivariable analyses, we also used data from later admissions, in an extended Cox model (survival) $)^{22,23}$ and a linear mixed model (LMM) (associations with NT-proBNP). ${ }^{24,25}$

\section{Analysis of mortality}

All variables that were associated with both pulmonary congestion ( $P<0.20$ with either radiological assessment) and mortality (logrank $P<0.20)$ were included in a Cox regression analysis with time-dependent covariables (ie, allowing update of a patient's data on repeat admissions). Using a backward elimination procedure, the model was reduced by removing variables with $P>0.05$ provided that the coefficient of the association between mortality and any radiological assessment changed less than $20 \%$. Age and sex were kept in the model by convention, and both radiological assessments were kept for comparison. The proportional hazards assumption was checked by the Martingale residuals.

\section{Analysis of NT-proBNP}

The variables that were associated with pulmonary congestion (in the baseline analyses) and NT-proBNP concentration $(P<0.20$ in bivariable analysis) were included in a LMM along with age, sex, and both radiological assessments. The advantage of the LMM is that unbalanced data (the number of observations and the time elapsed between them are different between the patients) can be analyzed without introducing bias. ${ }^{25}$ We could therefore include all observations in this analysis. The model was manually backward reduced by removing variables with $P>0.05$ unless their removal increased the Akaike information criterion (AIC) statistic (ie, resulting in poorer model fit).

All the analyses were performed using SAS 9.2 (SAS Institute Inc., Cary, NC, USA).

\section{Results}

\section{Baseline analyses}

The mean age at inclusion was 71.5 years (standard deviation [SD] 9.0), and the mean $\mathrm{FEV}_{1} / \mathrm{FVC}$ was $45 \%$ (SD 0.14\%). The chest radiograph was missing for one admission, thus, 218 admissions, from 99 patients, constituted the study sample. The patient characteristics, grouped by evaluation of their chest radiographs at inclusion, are shown in Table 1 for those variables that differed $(P<0.20)$ within any radiographic assessment. Lung function was included to better characterize the cohort. Among the variables that were not significantly different at baseline were smoking status (48\% active or recent smokers), history of coronary artery disease $(27 \%)$, history of diabetes mellitus ( $8 \%)$, leucocyte count (mean $11.1 \times 10^{9} / \mathrm{L}$, SD 5.0), serum creatinine 
Table I Characteristics of patients with and without pulmonary congestion at baseline, assessed by standardized and routine procedure

\begin{tabular}{|c|c|c|c|c|c|c|}
\hline & \multicolumn{3}{|c|}{ Pulmonary congestion by standardized assessment } & \multicolumn{3}{|c|}{ Pulmonary congestion by routine assessment } \\
\hline & $\begin{array}{l}\text { Present } \\
(n=16)\end{array}$ & $\begin{array}{l}\text { Not present } \\
(n=83)\end{array}$ & $P$-value & $\begin{array}{l}\text { Present } \\
(n=\mid 4)\end{array}$ & $\begin{array}{l}\text { Not present } \\
(n=85)\end{array}$ & $P$-value \\
\hline Age, years & $73.3(9.6)$ & $71.1(8.8)$ & 0.419 & $76.0(8.7)$ & $70.7(8.8)$ & 0.049 \\
\hline Female & $8(50 \%)$ & $39(47 \%)$ & 0.825 & $6(43 \%)$ & $4 \mid(48 \%)$ & 0.709 \\
\hline \multicolumn{7}{|l|}{ Medical history } \\
\hline History of HF & $7(44 \%)$ & $7(8.4 \%)$ & 0.0002 & $4(29 \%)$ & $10(12 \%)$ & 0.108 \\
\hline History of HT & $9(56 \%)$ & $22(27 \%)$ & 0.019 & $6(43 \%)$ & $25(29 \%)$ & 0.315 \\
\hline $\mathrm{FEV}_{1}$, liter & $0.84(0.35)$ & $0.93(0.47)$ & 0.777 & $\mathrm{I} .0 \mathrm{I}(0.50)$ & $0.90(0.44)$ & 0.576 \\
\hline $\mathrm{FEV}_{1} / \mathrm{FVC}, \%^{\mathrm{a}}$ & $0.43(0.09)$ & $0.46(0.15)$ & 0.799 & $0.43(0.11)$ & $0.46(0.15)$ & 0.688 \\
\hline BMI, kg/mª & $21.4(5.8)$ & $23.0(5.1)$ & 0.099 & $21.7(3.6)$ & $22.9(5.4)$ & 0.630 \\
\hline \multicolumn{7}{|l|}{ Findings on admission } \\
\hline Peripheral edema & 7 (44\%) & II (I3\%) & 0.004 & $3(21 \%)$ & $15(18 \%)$ & 0.715 \\
\hline Heart rate, $\min ^{-1}$ & $100.8(16.9)$ & $100.9(23.5)$ & 0.739 & $90.4(18.4)$ & $102.6(22.7)$ & 0.055 \\
\hline $\mathrm{SaO}_{2}, \%$ & $83.2(8.2)$ & $91.0(5.9)$ & 0.0001 & $87.2(7.7)$ & $90.1(6.7)$ & 0.087 \\
\hline $\mathrm{PaCO}_{2}, \mathrm{kPa}^{\mathrm{a}}$ & $6.9(2.1)$ & $5.9(1.4)$ & 0.097 & $6.4(1.9)$ & $6.0(1.5)$ & 0.333 \\
\hline $\mathrm{PaO}_{2}, \mathrm{kPa}^{\mathrm{a}}$ & $6.8(1.5)$ & $8.6(1.8)$ & 0.0004 & $7.7(2.4)$ & $8.4(1.7)$ & 0.127 \\
\hline \multicolumn{7}{|l|}{ Biochemistry } \\
\hline CRP, mg/L & $67(22-88)$ & $26(9-66)$ & 0.078 & $60(40-74)$ & $25(9-72)$ & 0.088 \\
\hline NT-proBNP, pg/mL & $2,68 I(585-3,57 \mid)$ & 339 (150-973) & 0.001 & $2,33 \mathrm{I}(35 \mathrm{I}-3,483)$ & $370(145-1,019)$ & 0.005 \\
\hline \multicolumn{7}{|l|}{ Chest radiograph } \\
\hline Patient supine & $12(75 \%)$ & $26(31 \%)$ & 0.002 & $7(50 \%)$ & 31 (36\%) & 0.335 \\
\hline Infiltrate & $4(25 \%)$ & 7 (8.4\%) & 0.075 & $2(14 \%)$ & $9(11 \%)$ & 0.653 \\
\hline \multicolumn{7}{|l|}{ ECG } \\
\hline Atrial fibrillation & $2(13 \%)$ & $5(6.0 \%)$ & 0.315 & $4(29 \%)$ & $3(3.5 \%)$ & 0.007 \\
\hline Prior $\mathrm{MI}$ on ECG & $9(56 \%)$ & $26(31 \%)$ & 0.056 & $4(29 \%)$ & $31(36 \%)$ & 0.765 \\
\hline
\end{tabular}

Notes: The data are presented as numbers (percent of the column total), mean (standard deviation), or median (interquartile range). The table includes variables that differ $(P<0.20)$ between the presence and absence of CHF in any of the two radiological assessments. Age, sex, and lung function were included by convention. ${ }^{\mathrm{S} S p i r o m e t r y, ~ B M I, ~}$ and blood gas were available for 88,94 , and 97 patients, respectively.

Abbreviations: BMI, body mass index; $\mathrm{CHF}$, congestive heart failure; CRP, C-reactive protein; ECG, electrocardiogram; FEV , forced expiratory volume in I second; FVC, forced vital capacity; HF, heart failure; $\mathrm{HT}$, arterial hypertension; $\mathrm{MI}$, myocardial infarction; NT-proBNP, N-terminal prohormone of brain natriuretic peptide; PaCO, arterial partial pressure of $\mathrm{CO}_{2} ; \mathrm{PaO}_{2}$, arterial partial pressure of $\mathrm{O}_{2} ; \mathrm{SaO}_{2}$, arterial oxygen saturation.

(median $66 \mu \mathrm{mol} / \mathrm{L}$, interquartile range [IQR] 54-88), and CIIS $(38 \%$ had a score $\geq 20)$.

Of all 218 radiographs, $195(89 \%)$ were ruled negative for pulmonary congestion, by routine clinical assessment. In 32 of these $(16 \%)$, the standardized assessments were positive. The corresponding numbers using the index observations only were 10 of 85 radiographs (12\%). The features suggesting pulmonary congestion in the 32 radiographs were interstitial edema in two cases, enlarged vessels in the apex in 22 cases, Kerley B lines in one case, perihilar haze in 13 cases, and peribronchial cuffing in eight cases. Figure 1 shows two radiographs (selected at random), which were considered negative by the routine assessment but positive for apical blood vessels and perihilar haze by the standardized assessment.

In the ten baseline observations that were negative in the routine assessment but positive in the standardized assessment, the median NT-proBNP concentration was $1,027 \mathrm{pg} / \mathrm{mL}$ (IQR 400-3,426). Conversely, among the eight baseline observations that were positive in the routine assessment and negative in the standardized assessment, the median NTproBNP concentration was $397 \mathrm{pg} / \mathrm{mL}$ (IQR 271-1,859).

\section{Survival analyses}

During a median follow-up time of 1.9 years, 57 patients died. Of these, 15 had pulmonary congestion by the standardized assessment (sensitivity $26 \%$, specificity $98 \%$, ROC area 0.62

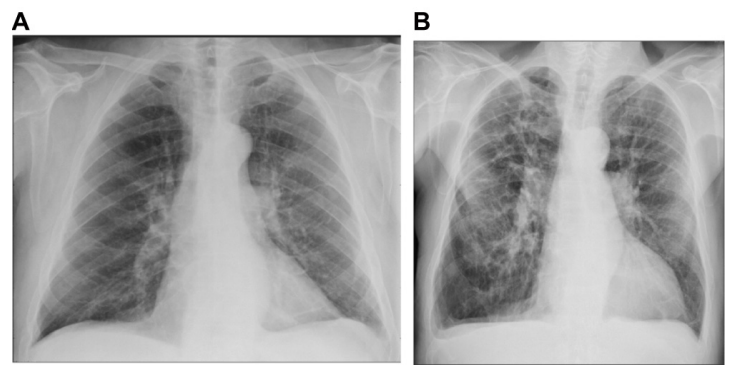

Figure I Randomly selected chest radiographs assessed negative in the routine assessment and positive in the standardized assessment.

Notes: (A) FEV $=2.3 \mathrm{~L}, \mathrm{FEV} / \mathrm{FVC}=0.6, \mathrm{NT}$-proBNP $=109 \mathrm{pg} / \mathrm{mL}$. (B) $\mathrm{FEV},=1.0 \mathrm{~L}$, $\mathrm{FV}_{1} / \mathrm{FVC}=0.38, \mathrm{NT}$-proBNP $=4,310 \mathrm{pg} / \mathrm{mL}$.

Abbreviations: $F E V$, forced expiratory volume in I second; FVC, forced vital capacity; NT-proBNP, N-terminal prohormone of brain natriuretic peptide. 
[95\% confidence interval (CI) 0.56-0.68]), and eleven had pulmonary congestion by the routine assessment (sensitivity $19 \%$, specificity $93 \%$, ROC area 0.54 [0.496-0.63]). Comparing the ROC, the standardized assessment proved superior in predicting death ( $P=0.022$, Figure 2$)$. Figure 3 shows patient survival, stratified by radiological assessment. The overall mortality rate was 28.7 per 100 patient-years (95\% CI: 22.1-37.2). Among the patients positive and negative for pulmonary congestion by the standardized assessment, the mortality rates were 111 (95\% CI: 67.1-185) and 22.7 (95\% CI: 16.8-37.2), respectively (logrank $P<0.0001$ ). The corresponding mortality rates by the routine assessment were 56.0 (95\% CI: 31.0-101) and 25.7 (95\% CI: 19.2-34.3), with logrank $P=0.039$.

Of the variables in Table 1, $\mathrm{PaCO}_{2}$, serum CRP, and ECG changes were not associated with mortality (age-adjusted logrank $P>0.20$ ). There was a trend towards increasing mortality with lung function below the mean $\left(\mathrm{FEV}_{1}<0.9 \mathrm{~L}\right.$ and $\mathrm{FEV}_{1} / \mathrm{FVC}<0.45$ [age-adjusted logrank $P=0.093$ and $P=0.103$, respectively]), but as this was not associated with any radiological assessment (Table 1), it was not included in further analyses. Patient survival, by the remaining covariables, is shown in Tables 2 and 3. Reducing the model resulted in the final model shown in Table 4. Of the two radiological evaluations, only the standardized assessment proved significantly associated with long-term mortality. The other variables in the model were age, sex, peripheral edema, and patient posture. As three observations had missing data on peripheral edema, this analysis was based on 215 observations.

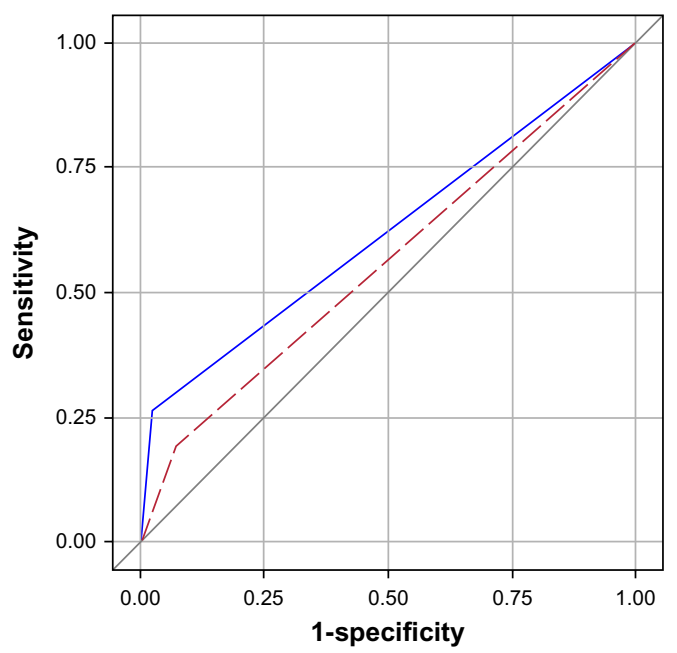

Figure 2 ROC curves for the routine (red dashed) and standardized (blue) assessments.

Notes:Age-adjusted logrank $P<0.000$ I between R-/S- and R-/S+;age-adjusted $P=0.049$ between $\mathrm{R}+/ \mathrm{S}-$ and $\mathrm{R}-/ \mathrm{S}+$. The results were based on the 99 index admissions. Abbreviations: COPD, chronic obstructive pulmonary disease; $\mathrm{R}-$, radiological assessment negative; $\mathrm{R}+$, radiological assessment positive; $\mathrm{S}-$, standardized assessment negative; S+, standardized assessment positive; ROC, receiver-operating characteristics.
Table 2 Number of mortalities (with mortality rates per 100 patient-years) in patients with AECOPD, by selected dichotomous covariables

\begin{tabular}{llll}
\hline Covariable & No & Yes & P-value $^{\mathbf{a}}$ \\
\hline Female sex & $27(25)$ & $30(34)$ & 0.250 \\
History of HF & $46(26)$ & II (59) & 0.019 \\
History of HT & $34(23)$ & $23(44)$ & 0.034 \\
AF on admission & $5 \mathrm{I}(27)$ & $6(64)$ & 0.078 \\
Peripheral edema & $40(23)$ & $17(8 \mathrm{I})$ & $<0.000 \mathrm{I}$ \\
Supine posture & $28(2 \mathrm{I})$ & $29(46)$ & 0.003 \\
Radiological infiltrate & $49(27)$ & $8(47)$ & 0.186 \\
\hline
\end{tabular}

Note: a Logrank $P$-value for equality of survival.

Abbreviations: AECOPD, acute exacerbation of COPD; COPD, chronic obstructive pulmonary disease; $A F$, atrial fibrillation; $\mathrm{HF}$, heart failure; $\mathrm{HT}$, hypertension.

\section{Validation against NT-proBNP}

Several of the variables that differed between the radiological assessments also showed an association with NT-proBNP concentration. These variables were age, BMI, history of HF, edema and atrial fibrillation on admission, heart rate, mean arterial pressure, $\mathrm{SaO}_{2}, \mathrm{PaO}_{2}, \mathrm{PaCO}_{2}$, serum CRP, and patient posture. Tables 5 and 6 show the geometric means of baseline NT-proBNP concentrations and the corresponding $P$-values for these variables.

When these variables were included in a LMM, a model with fixed effects only (ie, no random effects) and a spatial linear covariance structure had the lowest AIC (the best fit). Reduction of the full model resulted in the final model shown in Table 7, adjusting for sex and statistically significant associations. With the standardized assessment, the NT-proBNP concentrations were $50 \%$ higher in patients with pulmonary congestion than in patients without (ratio 1.8 [95\% CI: $1.2-2.6][P=0.003])$. Using the routine assessment, there was no significant difference in NT-proBNP concentration (ratio $1.6[0.96-2.6][P=0.069]$ ).

\section{Discussion}

In this study, a standardized, liberal assessment of pulmonary congestion on chest radiographs obtained on admission for AECOPD identified a group of patients at increased risk of dying, which was not reported by routine radiological assessment. The standardized assessment was also more strongly associated with NT-proBNP concentrations, indicating that this assessment more accurately identified concomitant HF with pulmonary congestion. A higher awareness of HF among COPD patients is warranted as it may have therapeutic consequences.

Although we applied accepted criteria for diagnosing pulmonary congestion, ${ }^{8,26}$ our standardized assessment may be regarded as liberal. Applying a liberal definition inher- 
Table 3 Number of mortalities (with mortality rates per 100 patient-years) in patients with AECOPD, by quartiles of selected continuous covariables

\begin{tabular}{llllll}
\hline Covariable (with quartile limits) & Q1 & Q2 & Q3 & Q4 & -value $^{\mathbf{a}}$ \\
\hline Age, years $(63.8 ; 71.4 ; 78.6)$ & $8(14)$ & $14(26)$ & $15(33)$ & $20(48)$ & 0.030 \\
$\mathrm{BMI}, \mathrm{kg} / \mathrm{m}^{2}(19.5 ; 21.9 ; 25.4)^{\dagger}$ & $15(35)$ & $17(47)$ & $10(18)$ & $11(19)$ & 0.043 \\
$\mathrm{SaO}_{2}, \%(87 ; 92 ; 94)$ & $21(76)$ & $13(25)$ & $7(11)$ & $16(30)$ & $<0.000 \mathrm{I}$ \\
$\mathrm{PaO}_{2}, \mathrm{kPa}(7.0 ; 8.2 ; 9.4)^{\dagger}$ & $20(69)$ & $13(25)$ & $10(17)$ & $13(23)$ & 0.001 \\
\hline
\end{tabular}

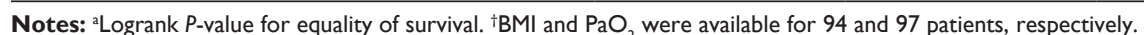

Abbreviations: AECOPD, acute exacerbation of COPD; COPD, chronic obstructive pulmonary disease; $\mathrm{BMI}$, body mass index; $\mathrm{PaO}$, arterial partial pressure of oxygen; $\mathrm{SaO}_{2}$, arterial oxygen saturation.

Table 4 Hazard ratios (with 95\% confidence intervals) for dying during a median of 1.9 years follow up after acute exacerbation of COPD

\begin{tabular}{lll}
\hline Covariable & Hazard ratio $(95 \% \mathrm{Cl})$ & $P$-value \\
\hline Age (per 5 years) & $1.2(1.01-1.4)$ & 0.036 \\
Female sex & $1.8(1.006-3.2)$ & 0.048 \\
Peripheral edema & $2.5(1.4-4.8)$ & 0.004 \\
Supine posture & $1.8(1.008-3.2)$ & 0.047 \\
Pulmonary congestion & $1.7(0.85-3.5)$ & 0.128 \\
by routine assessment & & \\
Pulmonary congestion by & $2.4(1.2-4.7)$ & 0.016 \\
standardized assessment & & \\
\hline
\end{tabular}

Note: The hazard ratios were based on 215 observations in 99 patients in an extended Cox regression analysis.

Abbreviations: $\mathrm{Cl}$, confidence interval; COPD, chronic obstructive pulmonary disease.

Table 5 Geometric mean (with number of observations) of baseline NT-proBNP concentration $(\mathrm{pg} / \mathrm{mL})$, by selected dichotomous variables

\begin{tabular}{llll}
\hline Covariable & No & Yes & P-value $^{\mathbf{a}}$ \\
\hline Female sex & $600(60)$ & $573(57)$ & 0.880 \\
History of HF & $429(85)$ & $930(14)$ & 0.063 \\
AF on admission & $438(92)$ & $1,537(7)$ & 0.026 \\
Peripheral edema & $514(8 I)$ & $909(18)$ & 0.037 \\
Supine posture & $363(61)$ & $746(38)$ & 0.015 \\
\hline
\end{tabular}

Note: ${ }^{\text {a }}$-test $P$-value for the difference in the natural logarithm of NT-proBNP concentrations.

Abbreviations: AF, atrial fibrillation; HF, heart failure; NT-proBNP, N-terminal prohormone of brain natriuretic peptide.

Table 6 Geometric mean of baseline NT-proBNP concentrations $(\mathrm{pg} / \mathrm{mL})$, by quartiles of selected continuous variables

\begin{tabular}{llllll}
\hline $\begin{array}{l}\text { Covariable (with quartile } \\
\text { limits) }\end{array}$ & QI & Q2 & Q3 & Q4 & P-value $^{\text {a }}$ \\
\hline Age, years $(63.8 ; 71.4 ; 78.6)$ & 207 & 380 & 492 & $\mathrm{I}, 3 \mathrm{II}$ & $<0.000 \mathrm{I}$ \\
$\mathrm{BMI}, \mathrm{kg} / \mathrm{m}^{2}(19.5 ; 21.9 ; 25.4)$ & 594 & 994 & $28 \mathrm{I}$ & $30 \mathrm{I}$ & 0.006 \\
$\mathrm{HR}, \mathrm{min}^{-1}(84 ; 99 ; \mathrm{II})$ & 782 & 318 & 438 & 495 & $0.18 \mathrm{I}$ \\
$\mathrm{SaO}_{2}, \%(87 ; 92 ; 94)$ & $\mathrm{I}, \mathrm{I} 34$ & 419 & 220 & 540 & 0.0005 \\
$\mathrm{PaO}_{2}, \mathrm{kPa}(7.0 ; 8.2 ; 9.4)$ & $89 \mathrm{I}$ & 362 & 326 & 499 & 0.070 \\
$\mathrm{PaCO}_{2}, \mathrm{kPa}(5.0 ; 5.7 ; 6.6)$ & 575 & 443 & 276 & 738 & 0.110 \\
$\mathrm{CRP}, \mathrm{mg} / \mathrm{L}(9 ; 29 ; 73)$ & 486 & 265 & 502 & $83 \mathrm{I}$ & 0.005 \\
\hline
\end{tabular}

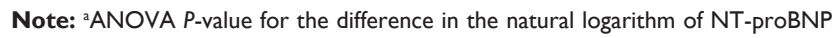
concentrations.

Abbreviations: ANOVA, analysis of variance; BMI, body mass index, CRP, C-reactive protein; HR, heart rate; NT-proBNP, N-terminal prohormone of brain natriuretic peptide; $\mathrm{PaO}_{2}$, arterial partial pressure of oxygen; $\mathrm{PaCO}_{2}$, arterial partial pressure of carbon dioxide; $\mathrm{SaO}_{2}$, arterial oxygen saturation. ently carries a risk of misclassifying normal radiographs as pathological. This error is expected to increase the sensitivity, but attenuate the specificity. However, in the present study, compared with the routine assessment, the association with both mortality and NT-proBNP became stronger using the standardized assessment. Both the sensitivity and specificity were higher, meaning that the standardized assessment not only identified more patients at risk of dying, but also, acquitted more patients with a better prognosis. Consequently, it was superior in identifying patients at risk of dying, as reflected by the greater (though admittedly still low) area under the curve (AUC) value in the ROC analysis. Hence, in order to detect patients at risk, clinicians as well as radiologists should pay more attention to the pulmonary vasculature, particularly the upper lung fields, in COPD patients hospitalized with worsening of dyspnea. It is not unlikely that such findings are overlooked as the underlying cause of the exacerbation in these patients is expected to be an acute inflammatory or infectious process in the airways.

We investigated the hypothesis that the standardized assessment identified more patients with increased

Table 7 Relative concentration of NT-proBNP in patients with acute exacerbation of COPD

\begin{tabular}{|c|c|c|}
\hline & $\begin{array}{l}\text { Relative } \\
\text { NT-proBNP }\end{array}$ & $P$-value \\
\hline Age (per 5 years) & $1.4(1.2-1.6)$ & $<0.0001$ \\
\hline Female & I.4 (0.84-2.2) & $0.221^{\mathrm{a}}$ \\
\hline CRP quartile & & $0.059^{\mathrm{b}}$ (for trend) \\
\hline I. $(<9 \mathrm{mg} / \mathrm{L})$ & I & \\
\hline 2. $(9-29 \mathrm{mg} / \mathrm{L})$ & I.I (0.75-I.6) & 0.635 \\
\hline 3. $(29-73 \mathrm{mg} / \mathrm{L})$ & I.3 (0.86-I.9) & 0.224 \\
\hline 4. $(\geq 73 \mathrm{mg} / \mathrm{L})$ & I.7 (I.I-2.7) & 0.014 \\
\hline $\begin{array}{l}\text { Pulmonary congestion by } \\
\text { routine assessment }\end{array}$ & $1.6(0.96-2.6)$ & 0.069 \\
\hline $\begin{array}{l}\text { Pulmonary congestion by } \\
\text { standardized assessment }\end{array}$ & $1.8(1.2-2.6)$ & 0.003 \\
\hline
\end{tabular}

Notes: The results were analyzed in a linear mixed model with 218 observations from 99 patients. ${ }^{\text {aSex }}$ was kept in the model by convention; ${ }^{\circ} \mathrm{CRP}$ was kept in the model in spite of $P>0.05$ as its removal resulted in poorer model fit.

Abbreviations: COPD, chronic obstructive pulmonary disease; CRP, C-reactive protein; NT-proBNP, N-terminal prohormone of brain natriuretic peptide. 


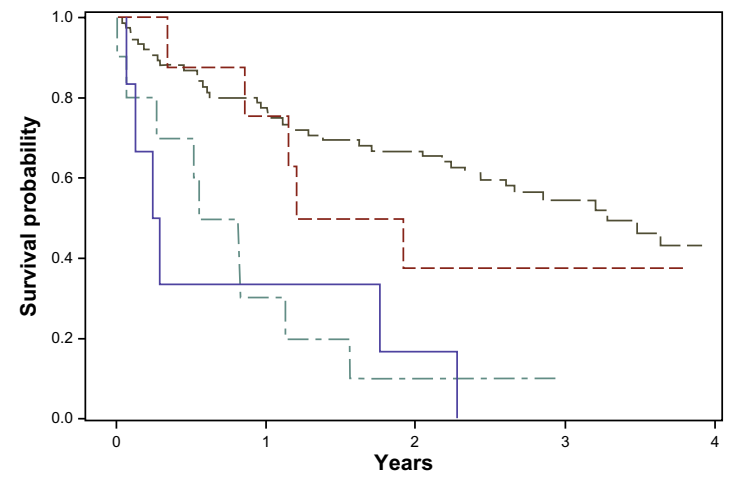

Figure 3 Survival after acute exacerbation of COPD, stratified by radiologic evaluation of pulmonary congestion on admission.

Notes: For the routine assessments, $A \cup C=0.54$; for the standardized assessments, $\mathrm{AUC}=0.62$.

Abbreviations: AUC, area under the curve; ROC, receiver operating characteristics.

NT-proBNP concentrations than did the routine assessment. The two assessments concurred with regard to pulmonary congestion in the majority of cases, and the NT-proBNP concentrations could not be expected to be significantly different between them. However, when compared in a multivariable analysis, only the standardized assessment remained associated with NT-proBNP. Among the observations that were negative in the routine assessment but positive in the standardized assessment, the NT-proBNP concentrations were relatively high. In two studies, ${ }^{27,28}$ NT-proBNP concentrations below 264 and $1,000 \mathrm{pg} / \mathrm{mL}$, respectively, were optimal to rule out $\mathrm{HF}$ in AECOPD, while $1,800 \mathrm{pg} / \mathrm{mL}$ and 2,500 pg/mL, respectively, were suggested to confirm the presence of concomitant HF. In light of this, many of the patients identified by the standardized, but not by the routine assessment, may have suffered from HF (as well as from COPD exacerbation) on admission. However, the diagnosis of left HF cannot be established by NT-proBNP alone as natriuretic peptides may originate from the right ventricle, particularly in these patients.

In all, $44 \%$ of the patients with pulmonary congestion found by the standardized assessment had a history of HF compared with $29 \%$ found with the routine assessment. The study investigators were blinded for all clinical data, but the clinicians who performed the initial assessment were not. Thus, despite potential information of known HF, the routine assessment was less likely to diagnose pulmonary congestion. There may have been some systematic clinical bias in that the radiologists were informed that the radiograph under investigation was from a COPD patient with (yet another) acute exacerbation. This may influence the radiologists to describe it as such, without specifically looking for signs of HF. Such an approach should be discouraged on the basis of our findings.
Radiological infiltrates and serum CRP both showed some association with the standardized assessment, mortality, and the NT-proBNP level, and one might speculate whether we have identified patients with lower airway infections rather than HF. The review of the patient records does not support this as the proportion of patients with a discharge diagnosis of pneumonia/airway infection was similar across the groups (data not shown).

The radiology fellow and the pulmonologist performing the standardized assessment had about the same experience as the attending and senior physicians, respectively, performing the routine assessments. The investigators, including a pulmonologist, performing the standardized assessment were of course aware that they did this as part of a study; the radiologists who performed the routine assessments were not. Moreover, one of our hypotheses was that unrecognized HF in COPD patients is common. Thus, the awareness of the investigators performing the standardized assessment was higher, and the threshold to rule in pulmonary congestion may have been lower. As they were blinded to the clinical data and objectively determined the presence or absence of predefined radiological features, we have sought to minimize this potential bias. However, it is noteworthy, if it proves true, that one can identify COPD patients at increased risk of dying simply by increasing the awareness of pulmonary congestion. Indeed, this is a key message from this study: To minimize the potential prejudice and subjectivity in the interpretations, radiographs from patients presenting with AECOPD should be systematically examined for signs of left HF as this may be challenging to diagnose clinically. If such signs are present, clinicians should take this into consideration. When identified, heart disease in COPD patients should be treated according to guidelines, as emphasized in the latest GOLD revision. ${ }^{29}$ Therefore, in contrast to the recommendation made in a recent review, ${ }^{8}$ we suggest chest radiography, an inexpensive and readily available procedure, to be performed as a routine examination in AECOPD.

In the multivariable analyses, we used data from 218 observations from 99 patients. By using statistical models described in standard textbooks, ${ }^{22-25}$ this can be done without introducing bias or inflating the results. Particularly regarding the survival analysis, each patient contributes, with observation time from inclusion to death or censoring. However, the patients are allowed to change on readmissions (for example from congestion to not congestion or from CRP first quartile to $\mathrm{CRP}$ third quartile). 


\section{Limitations}

Our study sample was quite small but was unselected. In spite of only 99 included patients, we showed a statistically significant difference in mortality between the two radiological assessments. Based on our results, a much larger sample would be needed to show significant differences in NT-proBNP.

This was a small single-center study, and we do not know to what extent the present findings can be generalized. The applicability of the assessment should be validated in other cohorts of COPD patients and different populations. Finally, there may be residual confounding in the material, ie, unidentified factors associated with radiologic interpretation and mortality.

\section{Conclusion}

By applying a standardized and liberal approach when evaluating pulmonary congestion on chest radiographs during AECOPD, a group of patients at increased risk of dying was identified. The observation that NT-proBNP concentrations were increased in these patients suggests that this may have been due, at least partially, to left-sided congestive heart failure. The systematic assessment of chest radiographs of COPD patients hospitalized for worsening of dyspnea may give important information that may guide their treatment.

\section{Author contributions}

All authors had full access to the original data and vouch for the completeness and veracity of the data and data analyses. All authors contributed to data interpretation and to the writing of the report, made final decisions on all parts of the report, and approved the final version of the submitted report. PHB, TO, and VS designed the study. PHB interviewed and enrolled the patients. ADH and VS confirmed the diagnoses, undertook the statistical analyses and generated tables and figures. VS and BDK reviewed the radiographs. ADH and PHB analyzed the ECGs.

\section{Acknowledgments}

The study was financed by The Norwegian Association of Heart and Lung Patients, through funds from the Norwegian Extra Foundation for Health and Rehabilitation. They played no role in the study design, collection of data, writing of the manuscript, or the decision to submit for publication.

The authors thank Dr Anke Neukamm, Akershus University Hospital, and Dr Lars Øivind Høiseth, Oslo University Hospital, for their assistance in analyzing the ECGs.

\section{Disclosure}

Torbjørn Omland has received speaker's honoraria from Abbott Diagnostics, Siemens Healthcare Diagnostics, and Roche Diagnostics; and research grant support from Abbott Diagnostics and Roche Diagnostics, through Akershus University Hospital. The authors report no other conflicts of interest in this work.

\section{References}

1. Curkendall SM, DeLuise C, Jones JK, et al. Cardiovascular disease in patients with chronic obstructive pulmonary disease, Saskatchewan Canada cardiovascular disease in COPD patients. Ann Epidemiol. 2006;16(1):63-70.

2. Fimognari FL, Scarlata S, Conte ME, Incalzi RA. Mechanisms of atherothrombosis in chronic obstructive pulmonary disease. Int JChron Obstruct Pulmon Dis. 2008;3(1):89-96.

3. Huiart L, Ernst P, Suissa S. Cardiovascular morbidity and mortality in COPD. Chest. 2005;128(4):2640-2646.

4. Sidney S, Sorel M, Quesenberry CP, DeLuise C, Lanes S, Eisner MD. COPD and incident cardiovascular disease hospitalizations and mortality: Kaiser Permanente Medical Care Program. Chest. 2005; 128(4):2068-2075

5. Muller N, Coxson H. Chronic obstructive pulmonary disease. 4: Imaging the lungs in patients with chronic obstructive pulmonary disease. Thorax. 2002;57(11):982-985.

6. Shaker SB, Dirksen A, Bach KS, Mortensen J. Imaging in chronic obstructive pulmonary disease. COPD. 2007;4(2):143-161.

7. McMurray JJ, Adamopoulos S, Anker SD, et al; ESC Committee for Practice Guidelines. ESC Guidelines for the diagnosis and treatment of acute and chronic heart failure 2012: The Task Force for the Diagnosis and Treatment of Acute and Chronic Heart Failure 2012 of the European Society of Cardiology. Developed in collaboration with the Heart Failure Association (HFA) of the ESC. Eur Heart J. 2012;33(14):1787-1847.

8. Cardinale L, Volpicelli G, Lamorte A, Martino J; Andrea Veltri. Revisiting signs, strengths and weaknesses of Standard Chest Radiography in patients of Acute Dyspnea in the Emergency Department. J Thorac Dis. 2012;4(4):398-407.

9. Brekke PH, Omland T, Smith P, Søyseth V. Underdiagnosis of myocardial infarction in COPD - Cardiac Infarction Injury Score (CIIS) in patients hospitalised for COPD exacerbation. Respir Med. 2008;102(9):1243-1247.

10. Buajordet I, Ebbesen J, Erikssen J, Brørs O, Hilberg T. Fatal adverse drug events: the paradox of drug treatment. J Intern Med. 2001;250(4): 327-341.

11. Macchia A, Rodriguez Moncalvo JJ, Kleinert M, et al. Unrecognised ventricular dysfunction in COPD. Eur Respir J. 2012;39(1):51-58.

12. Høiseth AD, Neukamm A, Karlsson BD, Omland T, Brekke PH, Søyseth V. Elevated high-sensitivity cardiac troponin $\mathrm{T}$ is associated with increased mortality after acute exacerbation of chronic obstructive pulmonary disease. Thorax. 2011;66(9):775-781.

13. Knudsen CW, Omland T, Clopton P, et al. Diagnostic value of B-Type natriuretic peptide and chest radiographic findings in patients with acute dyspnea. Am J Med. 2004;116(6):363-368.

14. Chang CL, Robinson SC, Mills GD, et al. Biochemical markers of cardiac dysfunction predict mortality in acute exacerbations of COPD. Thorax. 2011;66(9):764-768.

15. Medina AM, Marteles MS, Sáiz EB, et al. Prognostic utility of NTproBNP in acute exacerbations of chronic pulmonary diseases. Eur $J$ Intern Med. 2011;22(2):167-171.

16. Stolz D, Breidthardt T, Christ-Crain M, et al. Use of B-type natriuretic peptide in the risk stratification of acute exacerbations of COPD. Chest. 2008;133(5):1088-1094. 
17. Høiseth AD, Omland T, Hagve TA, Brekke PH, Søyseth V. NT-proBNP independently predicts long term mortality after acute exacerbation of COPD - a prospective cohort study. Respir Res. 2012;13:97.

18. Hawkins NM, Petrie MC, Jhund PS, Chalmers GW, Dunn FG, McMurray JJ. Heart failure and chronic obstructive pulmonary disease: diagnostic pitfalls and epidemiology. Eur J Heart Fail. 2009;11(2): $130-139$.

19. Høiseth AD, Omland T, Hagve TA, Brekke PH, Søyseth V. Determinants of high-sensitivity cardiac troponin $\mathrm{T}$ during acute exacerbation of chronic obstructive pulmonary disease: a prospective cohort study. BMC Pulm Med. 2012;12:22.

20. Rautaharju PM, Warren JW, Jain U, Wolf HK, Nielsen CL. Cardiac infarction injury score: an electrocardiographic coding scheme for ischemic heart disease. Circulation. 1981;64(2):249-256.

21. World Health Organization. The International Classification of Diseases (ICD). Available from: http://www.who.int/classifications/icd/en/. Accessed November 1, 2013.

22. Hosmer DW Jr, Lemeshow S, May S. Applied Survival Analysis. Regression Modeling of Time-to-Event Data. 2nd ed. Hoboken, NJ: Wiley-Interscience; 2008.
23. Kleinbaum DG, Klein M. Survival Analysis. A Self-Learning Text. 2nd ed. New York, NY: Springer; 2005.

24. Diggle PJ, Heagerty P, Liang KY, Zeger SL. Analysis of Longitudinal Data. Vol 2. Oxford: Oxford University Press; 2002.

25. Fitzmaurice GM, Laird NM, Ware JH. Applied Longitudinal Analysis. New York, NY: John Wiley \& Sons; 2004.

26. Novelline RA. Squire's Fundamentals of Radiology. 6th ed. Boston, MA: Harvard University Press; 2004.

27. Abroug F, Ouanes-Besbes L, Nciri N, et al. Association of left-heart dysfunction with severe exacerbation of chronic obstructive pulmonary disease: diagnostic performance of cardiac biomarkers. Am J Respir Crit Care Med. 2006;174(9):990-996.

28. Baggish AL, Siebert U, Lainchbury JG, et al. A validated clinical and biochemical score for the diagnosis of acute heart failure: the ProBNP Investigation of Dyspnea in the Emergency Department (PRIDE) Acute Heart Failure Score. Am Heart J. 2006;151(1):48-54.

29. goldcopd.org [homepage on the Internet]. From the global strategy for the diagnosis, management and prevention of COPD. Global Initiative for Chronic Obstructive Lung Disease (GOLD); 2013. Available from: http://www.goldcopd..org/. Accessed October 31, 2013.
International Journal of COPD

\section{Publish your work in this journal}

The International Journal of COPD is an international, peer-reviewed journal of therapeutics and pharmacology focusing on concise rapid reporting of clinical studies and reviews in COPD. Special focus is given to the pathophysiological processes underlying the disease, intervention programs, patient focused education, and self management protocols.

\section{Dovepress}

This journal is indexed on PubMed Central, MedLine and CAS. The manuscript management system is completely online and includes a very quick and fair peer-review system, which is all easy to use. Visit http://www.dovepress.com/testimonials.php to read real quotes from published authors. 